\title{
Aligning the eye to the actively or passively positioned hand ${ }^{1}$
}

MARTIN J. STEINBACH ${ }^{2}$ YORK UNIVERSITY

In a test of static alignment of the eye to the nonvisible fingertip, whether the hand was positioned by $S$ or by $E$ made no difference in the eye's consistency of localization of the fingertip. This result suggests that the outflow (efference) issued to move the arm was not supplying the oculomotor system with any more information about fingertip position than that already present from proprioceptive sources It is consistent with earlier findings on tracking self-moved targets where useful information in the efferent signal was concerned with the self-moved target's acceleration and velocity changes rather than its position.

Not surprisingly, an $\mathbf{S}$ can track a target visually more accurately when moved by him rather than if moved by some outside force (Steinbach \& Held, 1968). Appa:ently the oculomotor system has access to the efferent (or outflow) simual producing the target movements, making use of it to keep the target image on the fovea. This enhanced tracking performance could result conceivably from information either about the target's future position or motion. Steinbach (1969) has shown that it is the latter, i.e., the important information extracted from the outflow signal and used by the oculomotor system is dynamic; positional information about hand and arm location did not appear to be essential for the tracking task.

What about static alignments of the eye to the hand? While the above studies were all concerned with the moving hand and eye, the conclusion reached from them leads to a counterintuitive prediction: Since efference does not appear to be supplying explicit information about location but rather about change in motions, then there may be no differences between the eye's performance in locating an actively or a passively positioned limb. More specifically, the eye should not be any more consistent and reliable in orienting to the point in space the fingertip should occupy (although not actually visible) when the hand is positioned and held stationery by $S$ than when it is positioned by $\mathbf{E}$.

\section{Apparatus \\ METHOD \\ The apparatus is described in detail in Steinbach (1969). Briefly, it allowed}

simultaneous registration of eye position by using an infrared photoelectric technique, and of arm (and fingertip) position using a flat lever pivoted near the elbow, geared to a potentiometer. The S's head was held in a fixed position by a dental impression mouthbite. Interposed between his hand and eyes was a plane mirror, positioned so $\mathbf{S}$ saw the reflection of a ground-glass screen actually located in front of him but whose virtual image was at a distance corresponding to the distance from his eye to his fingertip $(30.5 \mathrm{~cm})$.

A narrow black line was drawn completely across the ground-glass screen along the approximate trajectory in which the fingertip moved when he pivoted his arm back and forth under the mirror. Thus, when asked to "look at" his fingertip, which lay somewhere directly underneath the line, $S$ would not make vertical misalignments that could produce a spurious output of the eye monitoring system (which was accurate only for horizontal displacements of the eye).

\section{Procedure}

In the active condition, $S$ was instructed to move his hand to a position and hold it there (constrained by stops to within $20 \mathrm{deg}$ in visual angle), look along the black line to the point he thought corresponded to where the fingertip would be if he could see it, and then operate a switch that recorded the position of the eye and the hand. The $S$ was instructed to "randomly" vary the positions adopted within the 20-deg limit. For the passive condition, $S$ relaxed his arm while $E$ moved the arm to a new position at about the

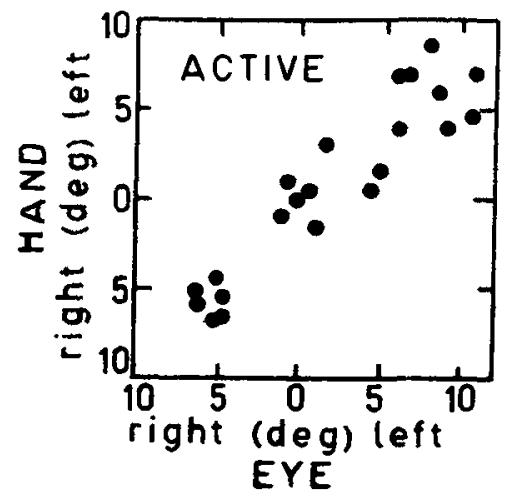

Fig. 1. Static alignments of eye to actively and passively positioned hand. same rate of motion as that used by $E$. The $S$ again looked to where he thought his fingertip lay and recorded the eye and hand positions. Eye position was recorded within $5 \mathrm{sec}$ after the hand was repositioned, in both the active and passive conditions. The order of testing was permuted, with some Ss tested first passively, and others tested first in the active condition. Each $S$ made about 15 to 20 alignments for each condition.

Eye position calibrations were taken at the beginning and end of each recording session. Only data where calibration was linear and maintained to within $1 \mathrm{deg}$ were kept for analysis.

\section{Subjects}

Five male undergraduates at M.I.T. were Ss, paid for their time. None had any noticeable degree of strabismus, although this was not formally tested.

\section{RESULTS}

The data from one $S$, shown in Fig. 1, depicts the results of S's attempts to orient his eye (abscissa) to his nonvisible fingertip (ordinate) when he has moved his arm into position (active condition, on left) and when $E$ has moved $S$ 's relaxed arm into position (passive, on right). Judging by the relative amount of scatter in the two conditions, there does not appear to be any difference between the two. In order to look for subtle differences in the orientation of the eye to the actively or passively placed limb, the correlation coefficient, readily obtainable from these data, was used as a measure of consistency of localization. Given a poor ability at

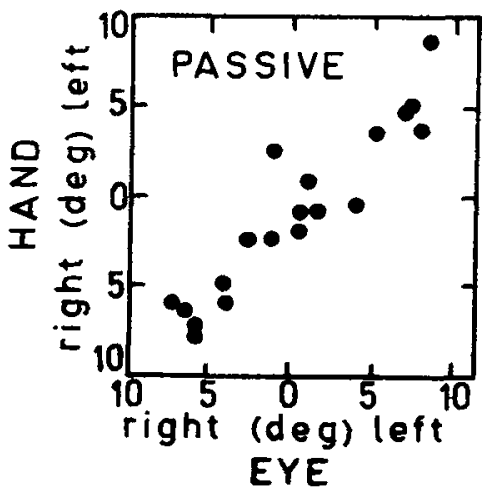


Table 1

Correlation Coefficients of Hand Vs Eye Position for Active and Passive Positioning of the Hand

\begin{tabular}{lcc}
\hline Ss & Active & Passive \\
\hline SM & .89 & .94 \\
CB & .96 & .98 \\
RF & .98 & .94 \\
BC & .93 & .93 \\
IS & .97 & .91 \\
Average & .946 & .940 \\
\hline
\end{tabular}

matching eye orientation to hand position, there should be considerable scatter in the plot of hand vs eye position, which would be indicated by a low correlation coefficient; conversely, consistent localization would be indicated by a high coefficient.

For the $S$ whose results are shown in Fig. 1, high and identical correlations (.93) for both active and passive conditions were obtained. The coefficients for all $S$ s are shown in Table 1, which indicates that no differences in consistency of localization exist between the active and passive conditions in this experiment.

The actual positional deviations of eye orientation from fingertip position were not calculated, but can be roughly estimated by examining Fig. 1. The magnitude of the deviations are comparable to results found by other investigators who used only the active mode (in our parlance) of hand positioning. Merton (1961) and Gibbs and Logan (1965) both report standard deviations of about $\pm 1.5 \mathrm{deg}$ in the scatter of misalignments of eye to hand, the approximate magnitude of the deviations found for the $S$ whose results appear in Fig. 1 and for the other $S s$ in this experiment.

\section{DISCUSSION}

The present experiment was not so much concerned with the size of the misalignments between eye orientation and hand position, but rather with any potential differences between alignment to the actively or passively positioned limb. Would the efference issued in actively positioning the arm supply any additional information to the oculomotor system? The assumption made was that if a monitored outflow did add to the orienting performance of the eye, then it would be reffected in a poorer performance under the passive condition where this information was missing and would be indicated by a larger scatter of misalignments of eye to hand. The absence of a difference between these two conditions would imply that outflow does not provide the oculomotor system with any added information about arm position than that already present from proprioceptive and kinesthetic sources.

The results appear to be at variance with those of another study which is somewhat comparable in design. Paillard and Brouchon (1968) showed that a $S$ would be more accurate when pointing a finger of one hand to a finger of his other hand when the target hand was actively, rather than passively, positioned. Their results indicate that in hand-hand alignment efference does provide positional information. It may be, however, that for the eye-hand system, proprioceptive information about hand position can get the eye initially aligned to within $3 \mathrm{deg}$ $( \pm 1.5 \mathrm{SD})$ and that after that, finer adjustments for foveal fixation are under visual control. ${ }^{3}$

Festinger and Canon (1965) showed in an experiment which is almost the inverse of the present one that efference from the oculomotor system did give information about spatial location. In their experiment, $S$ pointed his finger in the direction to which his eye had just made a saccade. The efference emitted to put the eye into its position by a saccadic movement, in their interpretation, gave the system positional information about its orientation. In the experiment reported here the efference emitted in the active condition was involved in the positioning of the hand and arm, and the results indicated that it did not-improve the eye's ability in orienting to the fingertip. Evidently hand-eye alignments and eye-hand alignments do not call into play bidirectionally acting mechanisms.

\section{REFERENCES}

ADLER, F. H. Physiology of the eye. (4th ed.) St. Louis: Mosby, 1965.

FESTINGER, L., \& CANON, L. K. Information about spatial location based on knowledge about efference. Psychological Review, 1965 . $72,373-384$

GIBBS, C. B., \& LOGAN, O. Tests of the functions of proprioception and in teraction of senses. Perceptual \& Motor Skills, 1965, 20 433-442.

MERTON, P. A. The accuracy of directing the eyes and the hand in the dark. Joumal of Physiology, 1961, 156, 555-577.

PALEARD, J., \& BROUCHON, M. Active and passive movements in the calibration of position sense. In S. J. Freedman (Ed.), The neuropsychology of spatially oriented behavior. Homewood, Ill: Dorsey Press, 1968. Pp. 37-55.

STEINBACH, M. J. Eye tracking of self-moved targets: The role of efference. Journal of Experimental Psychology, 1969, 82, 366-376.

STEINBACH, M. J., \& HELD, R. Eye tracking of observer-generated target movements. Science, $1968,161,187-188$.

\section{NOTES}

1. This researeh was conducted at M.I.T. while the author held a National Defense Education Act, Title IV, predoctoral fellowship. Additienal support came from National Institute of Mental Health Grant MH-07642 and National Aeronautics and Space Administration Grant NsG 496.

2. Address: Department of Psychology, York University, Downsview, Ontario, Canada.

3. A special relationship between hand position and eye orientation seems to be illustrated by a "trick" patients with left homonymous hemianopsias learn in order to read. Adler $(1965$, p. 511$)$ points out that they can read into the seeing half of the field but that they have difficulty in fixating the line. "These patients find little difficulty after practice since they learn to place a finger on the beginning of each line and direct the eyes in this manner to each new line [p. 511]."

(Accepted for publication January 28, 1970.) 